Fecha: $19 / 07 / 2021$

Medio: El Mercurio de Valparaíso

Pág. : 8

Cm2: 371,0

Supl.: El Mercurio de Valparaiso

Tipo: Actualidad

Título: Las tareas que tiene la Unidad Constituyente tras resultados de ayer
Tiraje:

Lectoría:

23.467

Favorabilidad:
70.400

$\square$ No Definida

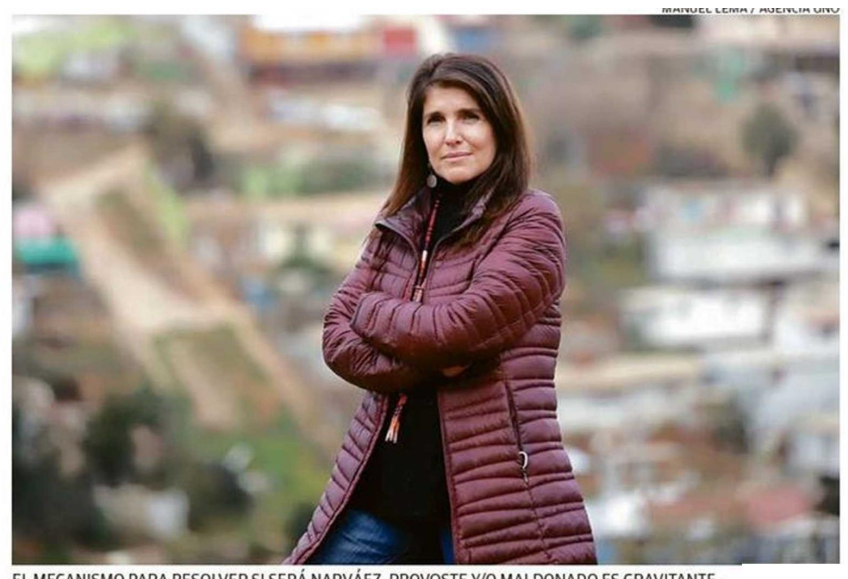

EL MECANISMO PARA RESOLVER SI SERÁ NARVÁEZ PROVOSTE Y/O MALDONADO ES GRAVITANTE.

\title{
Las tareas que tiene la Unidad Constituyente tras resultados de ayer
}

oposıcıón. La coalición busca acordar un mecanismo para definir entre Paula Narváez (PS) y Yasna Provoste (DC).

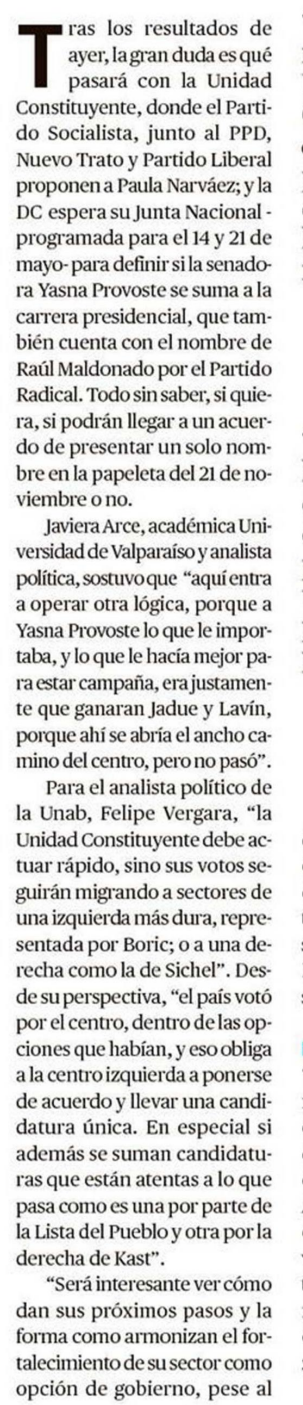

"Tenemosque resolver como Unidad Constituyente cuál es el mejor mecanismo para poder enfrentar de la mejor manera las elecciones de noviembre".

Eduardo Pastén Presidente regional del P

"No creo que se deba hacer una inferencia de que esos votos duros y seguros sean para uno u otro en un escenario presidencial de primera vuelta".

Daniel Verdess Diputado DC

desgaste de los partidos polít cos tradicionales y las demandas de una ciudadanía que está por cambios estructurales", sostuvo por su parte, Marcela sidad Autónoma.

DIFICIL PANORAM

"Si bien es un escenario que pace complejo para la Democracia Cristiana, opara nuestra candidata, yo no lo creo así", dice diputado DC Daniel Verdessi. Aunque en las horas previas a lo comicios, en la falange existía voces que ante un eventua triunfo de Boric, el escenario para senadora por Atacama er complejo, al no poder capitaliar el voto de centro.

El mismo Verdessi recono ce que el triunfodel magallánico fue el "del más moderado, del que tenía más posibilidades de dialogar y siempre buscó acuerdos, incluso con el Partido Socialista". "Algo parecido en Chile Vamos, donde tambiêngana una postura más moderada", agrega.

Sin embargo, "no creo que se deba hacer una inferencia de que esos votos duros y seguros sean para unou otro en un escenario presidencial de primera vuelta, porque yo sé de gente que votó por Boric para fienar a Jadue, porque tenían temor". Y esallidonde puede entrar la candidata o candidato de la Unidad Constituyente.

Peromientras todavía la candidatura de Yasna Provoste, Paula Narváez sigue en carrera, aunavin de Bachelet tenía previsto competir en las primarias de ayer, aunque elacuerdo no se concretó, yle restóun importantetiempoy pantalla para darse a conocer, que essu principal debilidad sobre todo para conquistar la izquierda más dura.

Sobre la opción de que la xministra termine declinando su opción, en su entorno aseguran que ese escenario es completamente inviable e, incluso, son varios latesisdeque ella compita directamente en primera vuelta.

Eduardo Pastén, presidente regional del Partido Socialista, aseguró que "tenemos que re. solver como Unidad Constituyente cuál es el mejor mecanismo para poder enfrentar de la mejor manera las elecciones de noviembre", pues se barajan opciones como consultas ciudadanas, una primaria virtual y una convencional “Eso es muy una convencional. Eso es muy importanteresolver ese tema",
finalizó. 